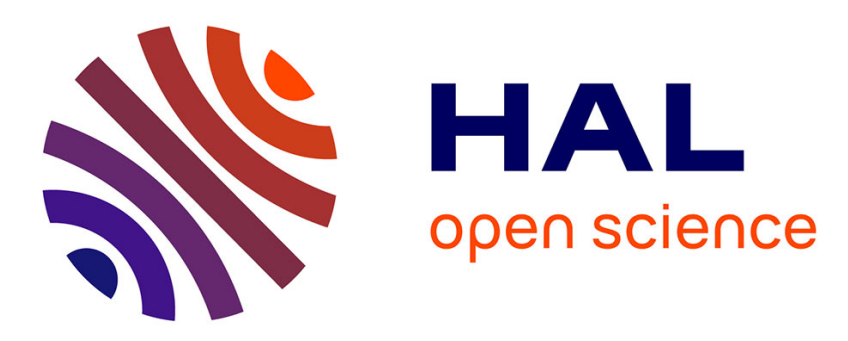

\title{
Formation and properties of Al composites reinforced by quasicrystalline $\mathrm{AlCuFeB}$ particles
}

\author{
Samuel Kenzari, Patrick Weisbecker, Marco Curulla, Guillaume Geandier, \\ Vincent Fournée, Jean-Marie Dubois
}

\section{- To cite this version:}

Samuel Kenzari, Patrick Weisbecker, Marco Curulla, Guillaume Geandier, Vincent Fournée, et al.. Formation and properties of $\mathrm{Al}$ composites reinforced by quasicrystalline $\mathrm{AlCuFeB}$ particles. Philosophical Magazine, 2008, 88 (05), pp.755-766. 10.1080/14786430801955253 . hal-00513871

\section{HAL Id: hal-00513871 \\ https://hal.science/hal-00513871}

Submitted on 1 Sep 2010

HAL is a multi-disciplinary open access archive for the deposit and dissemination of scientific research documents, whether they are published or not. The documents may come from teaching and research institutions in France or abroad, or from public or private research centers.
L'archive ouverte pluridisciplinaire HAL, est destinée au dépôt et à la diffusion de documents scientifiques de niveau recherche, publiés ou non, émanant des établissements d'enseignement et de recherche français ou étrangers, des laboratoires publics ou privés. 


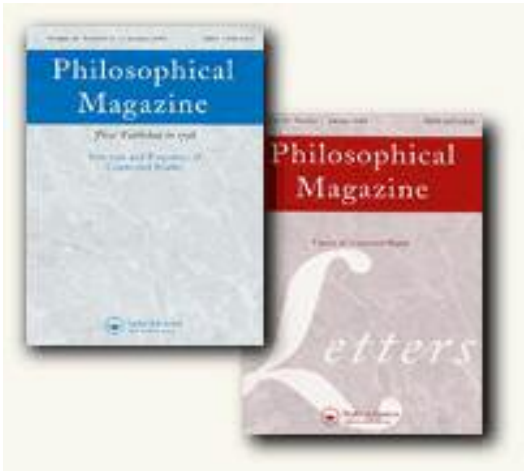

Formation and properties of Al composites reinforced by quasicrystalline AlCuFeB particles

\begin{tabular}{|r|l|}
\hline Journal: & Philosophical Magazine \& Philosophical Magazine Letters \\
\hline Manuscript ID: & TPHM-07-Aug-0227.R1 \\
\hline Journal Selection: & Philosophical Magazine \\
\hline Author: & 26-Jan-2008 \\
\hline Complete List of Authors: & $\begin{array}{l}\text { Kenzari, Samuel; Laboratoire de Science et Génie des Matériaux et } \\
\text { de Métallurgie (LSG2M), CNRS-UMR 7584; Institut Jean Lamour, } \\
\text { CNRS-INPL-UHP } \\
\text { Weisbecker, Patrick; Laboratoire des Composites } \\
\text { ThermoStructuraux, CNRS-UMR 5801 } \\
\text { Curulla, Marco; Laboratoire de Science et Génie des Matériaux et de } \\
\text { Métallurgie (LSG2M), CNRS-UMR 7584; Institut Jean Lamour, } \\
\text { CNRS-INPL-UHP } \\
\text { Geandier, Guillaume; Laboratoire de Métallurgie Physique, UFR } \\
\text { Sciences SP2MI; European Synchrotron Radiation Facility } \\
\text { Fournée, Vincent; Laboratoire de Science et Génie des Matériaux et } \\
\text { de Métallurgie (LSG2M), CNRS-UMR 7584; Institut Jean Lamour, } \\
\text { CNRS-INPL-UHP } \\
\text { Dubois, Jean-Marie; Laboratoire de Science et Génie des Matériaux } \\
\text { et de Métallurgie (LSG2M), CNRS-UMR 7584; Institut Jean Lamour, } \\
\text { CNRS-INPL-UHP }\end{array}$ \\
\hline Keywords: & $\begin{array}{l}\text { metal matrix composites, oxidation, phase transformations, } \\
\text { quasicrystals }\end{array}$ \\
\hline Keywords (user supplied): & \begin{tabular}{l} 
Tribological properties, Compressive properties \\
\hline
\end{tabular} \\
\hline
\end{tabular}




\section{S. ScholarONE"}




\title{
Formation and properties of Al composites reinforced by quasicrystalline $\mathrm{AlCuFeB}$ particles
}

\author{
S. KENZARI†ף, P. WEISBECKER $\$$, M. CURULLA $\uparrow$, G. GEANDIER $\$$, \\ V. FOURNEE†ף* and J. M. DUBOIS†ף \\ † Laboratoire de Science et Génie des Matériaux et de Métallurgie (LSG2M), CNRS-UMR \\ 7584, Parc de Saurupt, ENSMN, 54042 Nancy Cedex, France \\ I| Institut Jean Lamour, CNRS-INPL-UHP, Ecole des Mines, Parc de Saurupt, 54042 Nancy, \\ France \\ † Laboratoire des Composites ThermoStructuraux, CNRS-UMR 5801, 3 allée de la Boétie, \\ 33600 Pessac, France \\ \$ European Synchrotron Radiation Facility, 6 rue Jules Horowitz, BP 220, 38043 \\ GRENOBLE Cedex 9, France \\ $\S$ Laboratoire de Métallurgie Physique, UFR Sciences SP2MI, Boulevard Marie et Pierre \\ Curie, BP 30179 - 86962 Futuroscope Chasseneuil, France

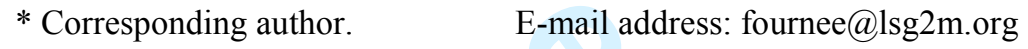

\begin{abstract}
Al-based composites reinforced by icosahedral (i-) $\mathrm{Al}_{59} \mathrm{Cu}_{25.5} \mathrm{Fe}_{12.5} \mathrm{~B}_{3}$ quasicrystalline particles were prepared by solid state sintering. It is found that $\mathrm{Al}$ diffusion from the matrix to the quasicrystalline particles induces phase transformation into the $\omega-\mathrm{Al}_{7} \mathrm{Cu}_{2} \mathrm{Fe}$ tetragonal phase. In order to preserve the $i$ phase, we use an oxidation pre-treatment of the particles and study its influence onto the kinetics of the phase transformation $(\mathrm{Al}+i \rightarrow \omega)$ as a function of the temperature by high energy X-ray diffraction. We show that the oxide layer acts as a barrier reducing efficiently the diffusion of $\mathrm{Al}$ up to a sintering temperature of $823 \mathrm{~K}$, allowing the control of the phases in the composites. The mechanical properties and the friction behaviour of the composites are investigated and show the negative influence of the oxide on the interface strength.
\end{abstract}

\section{Keywords:}

Quasicrystals; Al-based composite; Phase transformation; Oxidation; Tribological properties; Compressive properties. 


\section{Introduction}

Quasicrystals are aperiodic alloys possessing long range order and non crystallographic rotational symmetries like five-fold or ten-fold axis. They define a new class of materials with attractive properties, such as low friction coefficient, low adhesion and high wear resistance $[1,2]$. However, these properties could only be used for technological applications in the form of coatings [3] or reinforcement particles in metal matrix composites (MMC) [4] in order to circumvent their intrinsic brittleness. Al-based composites reinforced by $\mathrm{Al}-\mathrm{Cu}-\mathrm{Fe}$ quasicrystalline particles $(\mathrm{Al} /(\mathrm{AlCuFe}) \mathrm{p})$ were first studied by Tsai et al. [4]. They found that the hardness of the composite is increased by adding $i$-AlCuFe particles but noticed the appearance of the $\omega-\mathrm{Al}_{7} \mathrm{Cu}_{2} \mathrm{Fe}$ tetragonal phase during the formation process by sintering at $873 \mathrm{~K}$. More recently, Tang et al. reported the formation of ( $\mathrm{Al} /(\mathrm{AlCuFeB}) \mathrm{p})$ composites by either vacuum hot pressing or quasi-isostatic forging [5-8]. The quasicrystalline phase in the particles was found to transform into the $\omega$ phase during processing, producing compressive residual stresses in the Al matrix associated with an unusual strengthening. In order to preserve the $i$ phase, Fleury et al. [9] made similar MMC by using Ni-coated Al-Cu-Fe particles resulting in composites with a higher amount of $i$ phase. Recently [10], we reported that oxidation pre-treatments of the quasicrystalline particles also prevent the formation of the $\omega-\mathrm{Al}_{7} \mathrm{Cu}_{2} \mathrm{Fe}$ tetragonal phase during sintering, enabling the formation of composites containing no $\omega$ phase.

In this paper, we analyze the effect of temperature on the kinetics of the $(i \rightarrow \omega)$ phase transformation in $(\mathrm{Al} /(\mathrm{AlCuFeB}) \mathrm{p})$ composites for different oxidation pre-treatments of $\mathrm{Al}$ $\mathrm{Cu}-\mathrm{Fe}-\mathrm{B}$ particles. Icosahedral particles with nominal composition $\mathrm{Al}_{59} \mathrm{Cu}_{25.5} \mathrm{Fe}_{12.5} \mathrm{~B}_{3}$ was preferred to the canonical $\mathrm{Al}_{62} \mathrm{Cu}_{25.5} \mathrm{Fe}_{12.5}$ composition due to its higher yield stress and its lower friction coefficient [11-13]. The friction behaviour and the mechanical properties of sintered composites will also be discussed, with an emphasis on the influence of the oxidation pre-treatment on their properties.

\section{Experimental Procedure}

The $\mathrm{AlCuFeB}$ particles were produced by gas atomization. X-ray diffraction pattern of the powders can be indexed as a quasicrystalline phase containing a small amount of $\beta$-phase (cubic, $\mathrm{CsCl}$ type, $\mathrm{a} \approx 2.9 \AA$ ). This extra phase usually coexists with the quasicrystalline phase in gas atomized powders because it participates to the peritectic reaction by which the icosahedral phase is formed. The particles were then annealed at $873 \mathrm{~K}$ for 60 minutes, either in an evacuated tube $\left(10^{-5} \mathrm{mbar}\right)$ or in air. These pre-treatments result in almost pure icosahedral phase particles covered by either a thin (a few $\mathrm{nm}$ ) or a thick (a few tens of $\mathrm{nm}$ ) 
oxide layer $[14,15]$. Both $\mathrm{AlCuFeB}$ and commercial $\mathrm{Al}(99.98 \%)$ powders were then sieved with a mesh size of $25 \mu \mathrm{m}$ and blended in a planetary ball mill under an argon atmosphere at 200 tr. $\mathrm{min}^{-1}$ for $1 \mathrm{~min}$.

These powders were used to prepare two sets of three samples by cold isostatic pressing (1.6 $\mathrm{GPa}, 300 \mathrm{~K}$ ). Each set contain the same volume fraction of $i$-AlCuFeB particles (15 vol. \%), which were either pre-treated in vacuum or in air. In situ measurements by X-ray diffraction were performed on the ID15B beamline at the ESRF (European Synchrotron Radiation Facility, France) in order to quantify the kinetics of the phase transformation $(i \rightarrow \omega)$ during different thermal cycles. In the case of oxidized $i$-particles, the three composites were heated

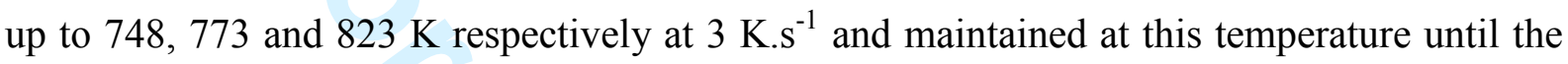
phase transformation was completed. In the case of non-oxidized particles, the temperatures were 723,773 and $823 \mathrm{~K}$. The radiation used was a high energy monochromatic X-ray beam of $89.25 \pm 0.02 \mathrm{keV}$. The experimental setup consisted of a furnace equipped with two halogen lamps (1000 W each) located in front of each other and surrounding the sample. The temperature was measured at different points, either with thermocouples welded directly on the sample or at fixed positions in the furnace. An image intensifier and a FReLoN CCD camera allowed to record one image every 5 seconds. The x-ray wavelength was determined by using aluminium powder as a reference material and was $0.013892 \mathrm{~nm}$. Finally, the range of $2 \theta$ angles investigated was $1.00-8.00^{\circ}$.

A third set of composites was prepared by sintering. Samples prepared by this way contained different volume fractions of $\mathrm{AlCuFeB}$ particles $(0,15,30$, and 60 vol. \%), either submitted or not to oxidation pre-treatments. Before sintering, the powders were placed in a carbon matrix and the chamber was evacuated at $10^{-3}$ mbar. The composites were sintered under low uniaxial pressure (32MPa) and in helium atmosphere (750 mbar) for $3.5 \mathrm{~h}$. After sintering, the surface of the samples was mechanically polished with SiC paper in water lubricant, from 500 grit down to 4000 grit. Samples were characterized after sintering by X-ray diffraction (XRD) using a SIEMENS D500 diffractometer (wavelength, $\lambda_{\text {CoKal }}=0.1788965 \mathrm{~nm}$ ) and Scanning Electron Microscopy (SEM). Friction properties were investigated with a pin on disk tribometer. Friction tests were carried out at room temperature in ambient atmosphere with a relative humidity of $50 \%$ and under non-lubricated conditions. The indenters used were 6 mm balls of either $100 \mathrm{Cr} 6$ hard steel, $\mathrm{Al}_{2} \mathrm{O}_{3}$ or $\mathrm{Si}_{3} \mathrm{~N}_{4}$. The sliding velocity was $0.5 \mathrm{~cm} . \mathrm{s}^{-1}$ and the normal load was $2 \mathrm{~N}$. The radius of the trace was $5 \mathrm{~mm}$. Hardness was measured by Brinell indentation with a $2.5 \mathrm{~mm}$ ball and a load of $62.5 \mathrm{daN}$ applied for $5 \mathrm{~s}$. Mechanical properties were evaluated by compression tests performed on samples $\left(3 \times 3 \times 10 \mathrm{~mm}^{3}\right)$ 
prepared from the bulk sintered composites and deformed along the longitudinal axis under a constant strain rate $\left(\dot{\varepsilon}=10^{-4} \mathrm{~s}^{-1}\right)$.

\section{Results and discussions}

\subsection{Isothermal kinetics of the $\omega$-phase formation}

\subsubsection{In situ high energy $X$-ray diffraction}

Figure 1 gives a three dimensional representation of the set of diffraction patterns acquired during the isothermal stage for a composite containing $15 \mathrm{vol} . \%$ of non-oxidized $i$ $\mathrm{AlCuFeB}$ particles prepared by cold isostatic pressing. At first, the sample only contains fcc aluminium and the $i$-AlCuFeB phase. The diffraction patterns obtained from composites containing pre-oxidized powders are similar, with no additional diffraction peaks, suggesting that the oxide layer is either amorphous or poorly crystallized and very thin. The phase transformation $i$-AlCuFeB $\rightarrow \omega-\mathrm{Al}_{7} \mathrm{Cu}_{2} \mathrm{Fe}$ is clearly observed in Figure 1, with the progressive disappearance of the (18/29) and (20/32) peaks of the $i$-phase and the simultaneous appearance of peaks corresponding to the $\omega$-phase. In all cases, the phase transformation starts during the isothermal stages allowing to observe the influence of the temperature on the kinetics of the $\omega$-phase formation.

Figure 2 shows the evolution of the volume fractions of the $\omega$-phase during the transformation $(i \rightarrow \omega)$ for the two sets of composites prepared by cold isostatic pressing. The phase fractions are determined using the integrated intensities of the main diffraction peaks for each phase. Absolute values are estimated thanks to calibration using the known initial volume fractions for the $\mathrm{Al} /(i-\mathrm{AlCuFe})$ composites or by using theoretical intensities calculated from structural data for the $\mathrm{Al} /(\omega-\mathrm{AlCuFe})$ composites resulting from the thermal treatment. The volume fraction $f v$ for each phase can be estimated using the following formulas:

$$
\begin{aligned}
& f v_{A l}=\frac{I_{A l(111)}}{I_{A l(111)}+K_{1} I_{i(18 / 29)}+K_{2} I_{\omega(214)}} \\
& f v_{i}=\frac{I_{i(18 / 29)}}{I_{i(18 / 29)}+K_{3} I_{\omega(214)}+K_{4} I_{A l(111)}} \\
& f v_{\omega}=\frac{I_{\omega(214)}}{I_{\omega(214)}+K_{5} I_{i(18 / 29)}+K_{6} I_{A l(111)}}
\end{aligned}
$$


where $f v_{\mathrm{Al}}+f v_{\mathrm{i}}+f v_{\omega}=1, I_{\mathrm{Al}(111)}, I_{i(18 / 29)}$ and $I_{\omega(214)}$ are the integrated intensities of the $\mathrm{Al}(111)$, $i$-phase (18/29) and $\omega$-phase (214) peaks respectively, $\mathrm{K}_{\mathrm{j}}(\mathrm{j}=1, \ldots, 6)$ are constants calculated using known initial volume fractions for $\mathrm{Al} /(i-\mathrm{AlCuFe})$ composites or by using theoretical intensities calculated from structural data for the $\mathrm{Al} /(\omega-\mathrm{AlCuFe})$ composite (Table 1$)$.

Figure 2 shows that the formation of the $\omega$-phase is much faster for composites containing non-oxidized $\mathrm{AlCuFeB}$ particles (series 1) rather than pre-oxidized particles (series 2). In the former case, the $i \rightarrow \omega$ transformation is almost completed after 0.3 hour at $823 \mathrm{~K}$ and after 2 hours at $773 \mathrm{~K}$ (a temperature of $723 \mathrm{~K}$ was not sufficient to induce the transformation). For pre-oxidized particles, the kinetics of the phase transformation is slower, even at high temperature, and the time to complete the transformation is approximately 3, 5 and 7 hours at 823,773 and $748 \mathrm{~K}$, respectively. This means that $\mathrm{Al}$ diffusion is reduced by the oxide barrier, opening a window to form $(\mathrm{Al} /(\mathrm{AlCuFeB}) \mathrm{p})$ composites containing only $\mathrm{Al}$ and the icosahedral phase by sintering up to $823 \mathrm{~K}$. Figure 2 also shows that the incubation time of the transformation, determined by the appearance of the first diffraction peak of the $\omega$ phase, increases when the temperature decreases and when the $\mathrm{AlCuFeB}$ particles are oxidized .

\subsubsection{Formation of the $\omega-\mathrm{Al}_{7} \mathrm{Cu}_{2} \mathrm{Fe}$ phase}

The isothermal mechanism of the phase transformation can be analyzed on the basis of the Johnson-Mehl-Avrami (JMA) law [16]:

$$
f v(t)=1-\exp \left(-(k t)^{n}\right)
$$

where $f v(t)$ is the transformed volume fraction of the $\omega$ phase, $t$ is the real time of the transformation, which is determined as the total time minus the incubation time, $k$ is the crystallization rate constant, and $n$ is the Avrami exponent reflecting the nature and geometry of the mechanisms of nucleation and growth during phase transformation. The value of $n$ can be determined using the following equation:

$$
\ln \{-\ln (1-f v(t))\}=n \ln (k)+n \ln (t)
$$

and plotting $\ln \{-\ln (1-f v(t))\}$ versus $\ln (t)$ for different temperatures allows to derive the exponent $n$. Figure 3 shows the JMA plots for the two series of composites over the range of transformed volume fraction between 10 and 90 vol. \%. The Avrami exponent takes a value of about $2.25 \pm 0.25$ (Table 2) for both series, independently of the temperature and of the pre-treatment. Based on the work of Christian [16], the $n$ exponent of the $i \rightarrow \omega$ transformation is consistent with a three-dimensional (3D) diffusion-controlled growth with decreasing nucleation rate. The growth of the first $\omega$ nuclei formed is faster than nucleation 
and growth of subsequent $\omega$ nuclei. The initial stage of the transformation could be controlled by a grain edge nucleation of the $\omega$ phase. In this case, nucleation could occur at the interface of two $i$ crystallites and the amorphous oxide layer.

The growth rate of the volume fraction of the $\omega$ phase can be determined by differentiation of the JMA equation:

$$
\frac{d(f v(t))}{d(t)}=n \cdot k^{n} t^{n-1} \cdot \exp \left(-(k t)^{n}\right)
$$

The growth rates for each series are listed in Table 2. As expected, the rates increase for nonoxidized $i$ particles. For comparison, growth rates of the $2^{\text {nd }}$ series are 2 times larger than for the first series at $773 \mathrm{~K}$ and 8 times larger at $823 \mathrm{~K}$. These results support further the fact that the oxide barrier is effective to prevent formation of the $\omega$ phase.

\subsection{Friction, hardness and compressive behaviours of bulk composites}

$\mathrm{Al} /(\mathrm{AlCuFeB}) \mathrm{p}$ composites were prepared by sintering, containing different particle volume fractions and using different pre-oxidized treatments of the $\mathrm{AlCuFeB}$ particles, either to prevent or to promote the formation of the $\omega$-phase. The fraction of the $\omega$-phase after sintering decreases with increasing oxidation time and almost vanishes for 100 hours of oxidation pre-treatment in air.

\subsubsection{Friction and hardness behaviours}

Using this set of composites, the influence of the $i$-phase on friction and hardness was tested. Table 3 summarizes the main characteristics of the different samples. Figure 4 shows the variation of the work of the friction force, calculated by integrating each friction curve over the first five meters of sliding. The work of the friction force decreases with increasing volume fraction of $\mathrm{AlCuFeB}$ particles, confirming our previous observation [10]. The Brinell hardness also increases with increasing volume fraction of $\mathrm{AlCuFeB}$ particles. The presence of the $i$-phase in $\mathrm{Al} /(\mathrm{AlCuFeB}) \mathrm{p}$ composites improves the friction and hardness properties less significantly than when the $\omega$-phase is present. This result may be explained by the embrittlement of the interface between the aluminium matrix and the icosahedral particles due to presence of the oxide layer. SEM investigations of the worn surface of the composites and indenters show that the $\mathrm{AlCuFeB}$ particles and counterpart balls are covered by a transferred layer which is made up primarily of aluminium and oxygen (not shown here). For composites containing 60 vol. $\%$ of $\mathrm{AlCuFeB}$ particles, the work of the friction force is divided by three and the hardness increased by a factor of 6 compared to the properties of the aluminium matrix. 
Different types of indenters (100Cr6 hard steel, $\mathrm{Al}_{2} \mathrm{O}_{3}$ and $\mathrm{Si}_{3} \mathrm{~N}_{4}$ ) have been used with the hope to avoid aluminium transfer during sliding. Alumina is an inert oxide and thus could limit material transfer. Silicon nitride is likely to react with aluminium and could modify the nature of the pin/composite interface by forming compounds of AlN or AlSi type. However, all the tests carried out presented a similar behaviour to those obtained with the $100 \mathrm{Cr} 6$ indenters within experimental accuracy, as shown in Figure 5. This can be explained by the high contact pressures in our experimental conditions (500 MPa), producing severe plastic deformation and coating of the indenter by Al transferred from the matrix. Therefore, the actual sliding body is no more hard steel or ceramic but essentially Al. Only at the beginning of the friction experiment does the nature of the sliding bodies have an influence on friction, before material transfer occurs. We observe that the friction coefficient ranges from 0.1 to 0.3 at the beginning of the sliding, depending on the composites, and then reaches a common value of about 0.6 after $5 \mathrm{~m}$ of sliding, independently of the sample as a result of material transfer.

\subsubsection{Compressive behaviour}

Compressive tests have been performed on the different samples listed in Table 4. Stressstrain curves obtained from room temperature compression tests are presented in Fig. 6. Data in Fig. 6a are for composites containing only the $\omega$-phase at different volume fractions whereas data in Fig. $6 \mathrm{~b}$ are for composites containing 15 vol. \% of pre-oxidized AlCuFeB particles. Measurements of yield strength $\sigma_{\text {yield }}$ of the different samples are shown in Table 5. The yield point $\sigma_{\text {yield }}$ was defined as the stress at $0.2 \%$ of plastic deformation. Although differences are observed in compression strain and strength, all composites have a similar compressive behaviour. After exceeding the yield stress, the stress increases with increasing deformation up to the ultimate compressive strength. A significant increase of the yield stress $\sigma_{\text {yield }}$ and the hardness was achieved by incorporating $\mathrm{AlCuFeB}$ particles into the pure aluminium matrix. High yield strength of $405 \mathrm{MPa}$ was obtained for the composite containing a volume fraction of particles of $45 \%$. Relative to the properties of the matrix, it corresponds to an increase of the yield stress $\left(\Delta \sigma_{0.2}\right)$ by $300 \mathrm{MPa}(290 \%)$ and of the hardness by $143 \mathrm{HB}$ (350 \%), respectively, as shown in Table 5. However, in the same time, the ductility of the composite is reduced. For comparison, Al composites reinforced with 40 vol. \% of SiC particles $(10-21 \mu \mathrm{m})$ have a $\Delta \sigma_{0.2}$ of about $150 \mathrm{MPa}$ [17]. As already mentioned by several studies $[5-9,18]$, the $\omega$ phase can be used as an effective reinforcement compared to commercial $\mathrm{Al}$ composites. Contrary to $\mathrm{Al} /(\mathrm{SiC}) \mathrm{p}$ composites the formation of the $\omega$ phase induces compressive residual stresses in the Al matrix associated with an unusual strengthening, as reported by Tang et al. [15, 17]. 
In the case of pre-oxidized $\mathrm{AlCuFeB}$ particles, the mechanical resistance and ductility are poorer although the $i$ phase is preserved (Fig. $6 \mathrm{~b}$ and Table 5). This is counterintuitive, since the mechanical properties of the $i$ phase are better than those of the $\omega$ phase and therefore improved properties of the composite should result as reported by Fleury et al. [9] and Tsai et al. [4]. The lower mechanical properties observed in our case can only be attributed to the embrittlement of the $\mathrm{Al} /$ particles interface due to the oxide layer. These results are consistent with several recent studies by Tang et al. [6-8] demonstrating the importance of the oxide layer thickness on the mechanical properties of similar composite materials. The embrittlement of the $\mathrm{Al} /$ particles interface is highlighted by observing the fracture surfaces of composite samples, either reinforced by $i$-AlCuFe particles or by $\omega$ $\mathrm{AlCuFe}$ particles. Figure 7 shows that fracture occurs at the Al/particles interface when particles have been oxidized. When non-oxidized particles are used, the fracture surface propagates through the reinforcement particles (Fig. 7(a)). Consequently, the formation of the $\omega$ phase enhances the bonding strength between the matrix and the particles due to interparticle diffusion during the solid state sintering process [ 5-9, 18].

\section{Conclusions}

Oxidation pre-treatment of the icosahedral quasicrystalline particles allowed us to reduce significantly the kinetics of $\mathrm{Al}$ diffusion from the matrix to the quasicrystalline particles for temperatures up to $823 \mathrm{~K}$. Consequently, composites made of $i-\mathrm{Al}_{59} \mathrm{Cu}_{25.5} \mathrm{Fe}_{12.5} \mathrm{~B}_{3}$ particles dispersed in a pure aluminium matrix with different volume fractions could be prepared by solid state sintering with low uniaxial pressure. This positive result is however weakened because the oxide layer causes embrittlement of the $\mathrm{Al} / i$ - $\mathrm{AlCuFeB}$ interfaces. Friction and mechanical properties of the composites have been measured for different compositions. A significant decrease of the work of the friction force and an increase of the mechanical properties is observed with increasing volume fraction of $\mathrm{AlCuFeB}$ particles, up to 60 vol. \%. The best mechanical properties are obtained when the reinforcement particles are totally transformed into tetragonal $\omega$-phase due to enhanced inter-particle bonding.

\section{Acknowledgements}

We would like to thank the staff of the ID15B beamline at the European Synchrotron Radiation Facility for technical assistance. We are grateful to S. Raffy (St Gobain) for the provision of quasicrystalline powders and to P. Delcroix for preparing samples by cold isostatic pressing. Help in SEM and compression test experiments by D. Bonina (LSG2M, 
Nancy) and O. Ferry (LPM, Nancy) is greatly acknowledged. This work was supported by the ADEME agency under contract nº 0366033 .

\section{References}

[1] J.M. Dubois, S.S. Kang and J. von Stebut, J. Mater. Sci. Lett. 10 (1991), 537.

[2] J.M. Dubois, P. Plaindoux, E. Belin-Ferré, N. Tamura, D.J. Sordelet, in: S. Takeuchi and T. Fujiwara, Editors, Proceedings of the Sixth International Conference on Quasicrystals, ICQ6, World Scientific, Singapore, (1997), 733.

[3] J.M. Dubois, S.S. Kang and Y. Massiani, J. Non-Cryst. Solids 153\&154 (1993), 443.

[4] A.P. Tsai, K. Aoki, A. Inoue and T. Masumoto, J. Mater. Res. 8, 1 (1993), 5.

[5] F. Tang, I.E. Anderson and S.B. Biner, J. of Light Metals 2, (2002), 201.

[6] F. Tang, I.E. Anderson and S.B. Biner, Mat. Sci. Eng. A 363, (2003), 20.

[7] F. Tang, I.E. Anderson, T. Gnaupel-Herold and H. Prask, Mat. Sci. Eng. A 383, (2004), 362.

[8] F. Tang, T. Gnaupel-Herold, H. Prask and I.E. Anderson, Mat. Sci. Eng. A 399, (2005), 99.

[9] E. Fleury, S.M. Lee, G. Choi, W.T. Kim, D.H. Kim, J. Mater. Sci. 36 (2001), 963.

[10] S. Kenzari, P. Weisbecker, G. Geandier, V. Fournée and J.M. Dubois, Phil. Mag. 86 , 35, (2006), 287.

[11] S.S. Kang and J.M. Dubois, Phil. Mag. A 66 (1) (1992), 151.

[12] P. Brunet, L.M. Zhang, D.J. Sordelet, M. Besser and J.M. Dubois, Mater. Sci. Eng. A 294 (2000), 74.

[13] J.M. Dubois, P. Archambault, L. Bresson and P. Cathonnet, French Patent N 9602224 (1996).

[14] G. Bonhomme, M. LeMieux, P. Weisbecker, V.V. Tsukruk and J.M. Dubois, J. NonCryst. Solids 334\&335 (2004), 532.

[15] P. Weisbecker, G. Bonhomme, G. Bott and J.M. Dubois, J. Non-Cryst. Solids 351 (2005), 1630.

[16] J.W. Christian, The theory of transformations in metals and alloys, Pergamon, London (1965).

[17] D.L. Mcdanels, Metal. Trans. A 16, (1985), 1105.

[18] S.M. Lee, J.H. Jung, E. Fleury, W.T. Kim et D.H. Kim, Mat. Sci. Eng. A 294-296, (2000), 99. 


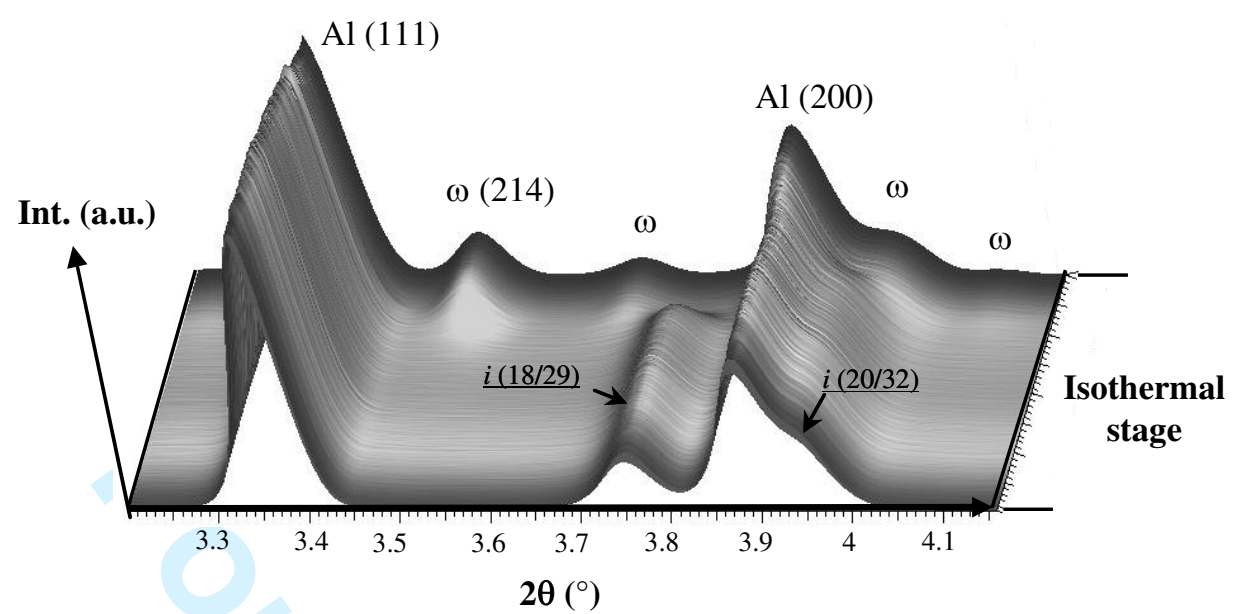

Figure 1. 3D representation of diffraction patterns obtained during an isothermal stage at $773 \mathrm{~K}$.

Table 1

$\mathrm{K}_{\mathrm{j}}$ values for volume fraction calculations.

\begin{tabular}{ccccccc}
\hline & $\mathrm{K}_{1}$ & $\mathrm{~K}_{2} *$ & $\mathrm{~K}_{3} *$ & $\mathrm{~K}_{4}$ & $\mathrm{~K}_{5} *$ & $\mathrm{~K}_{6} *$ \\
\cline { 2 - 7 } & 0.975 & 1.199 & 1.025 & 1.229 & 0.814 & 0.834 \\
\hline
\end{tabular}

*Constants calculated using theoretical intensities calculated from structural data for the $\mathrm{Al} 50 \mathrm{vol} . \%+\omega 50$ vol. \% composite. 


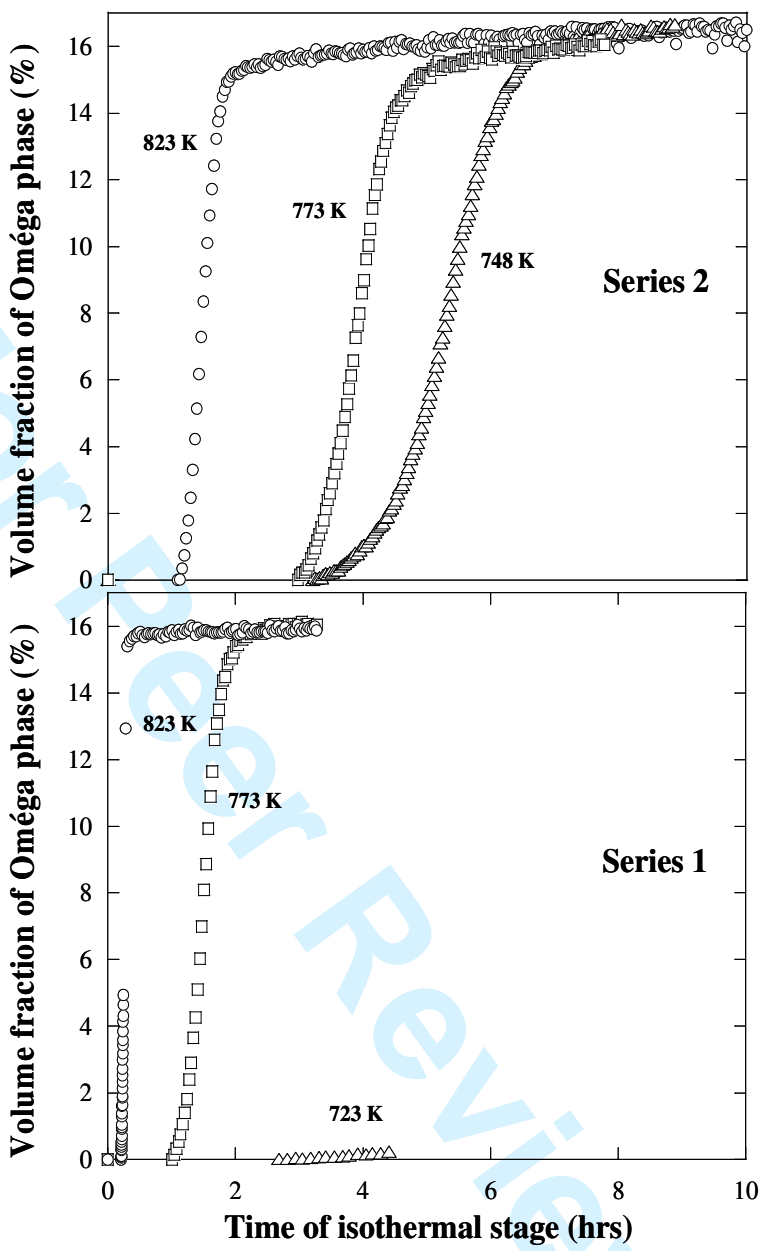

Figure 2. Top: Volume fraction of $\omega$-phase for the composites containing $i$-particles oxidized in air for 60 minutes as a function of time and isothermal temperatures. Bottom: volume fraction of $\omega$-phase for the composites containing $i$-particles annealed in vacuum for 60 minutes as a function of time and isothermal temperatures. 
Series 2

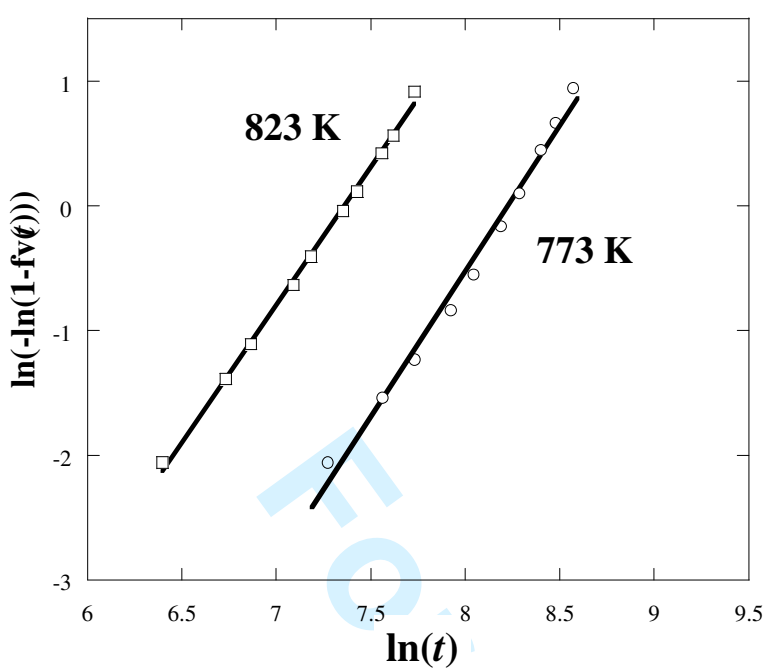

Series 1

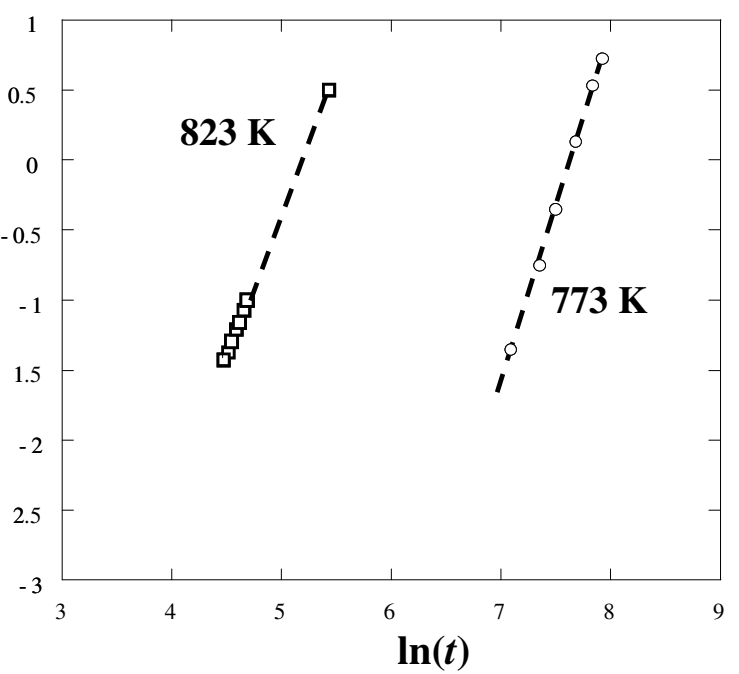

Figure 3. JMA plots for the two series of $\mathrm{Al} /(\mathrm{AlCuFeB}) \mathrm{p}$ composites. The slope of each line takes value of about $2.25 \pm 0.25$.

Table 2

Comparison of the main characteristic data of the $\omega$ phase formation.

\begin{tabular}{lcccc} 
& $\mathbf{T}_{\text {isothermal }}(\mathbf{K})$ & $\boldsymbol{n}$ & $\boldsymbol{k}\left(\mathbf{s e c}^{-\mathbf{1}}\right)$ & $\mathbf{d}\left(\mathbf{f} \mathbf{v}_{\boldsymbol{\omega}}\right) / \mathbf{d}(\mathbf{t}) \mathbf{m a x}\left(\mathbf{m i n}^{-\mathbf{1}}\right)$ \\
\hline \multirow{2}{*}{ Series 1 } & 773 & 2 & $4.8392 .10^{-4}$ & 0.029753 \\
& 823 & 2.5 & $5.6201 .10^{-4}$ & 0.28423 \\
\hline \multirow{2}{*}{ Series 2 } & 773 & 2.3 & $2.6803 .10^{-4}$ & 0.015361 \\
& 823 & 2.2 & $6.3634 .10^{-4}$ & 0.035102 \\
\hline
\end{tabular}

Table 3

Summary of the XRD analyses of samples.

\begin{tabular}{ccccc}
\hline Composite $^{\circ}$ & $\begin{array}{c}\text { Vol. \% } \\
\text { AlCuFeB }\end{array}$ & $\begin{array}{c}\text { Oxidation } \\
\text { Pre-Treatment }\end{array}$ & $\begin{array}{c}\text { XRD } \\
\text { before sintering }\end{array}$ & $\begin{array}{c}\text { XRD } \\
\text { after sintering }\end{array}$ \\
\hline 1 & 0 & - & $\mathrm{Al}$ & $\mathrm{Al}$ \\
2 & 15 & in vacuum & $\mathrm{Al}+i$ & $\mathrm{Al}+\omega$ \\
3 & 15 & in air for $100 \mathrm{~h}$ & $\mathrm{Al}+i$ & $\mathrm{Al}+i$ \\
4 & 30 & in vacuum & $\mathrm{Al}+i$ & $\mathrm{Al}+\omega$ \\
5 & 30 & in air for $75 \mathrm{~h}$ & $\mathrm{Al}+i$ & $\mathrm{Al}+i+\omega$ \\
6 & 60 & in vacuum & $\mathrm{Al}+i$ & $\mathrm{Al}+\omega$ \\
\hline
\end{tabular}

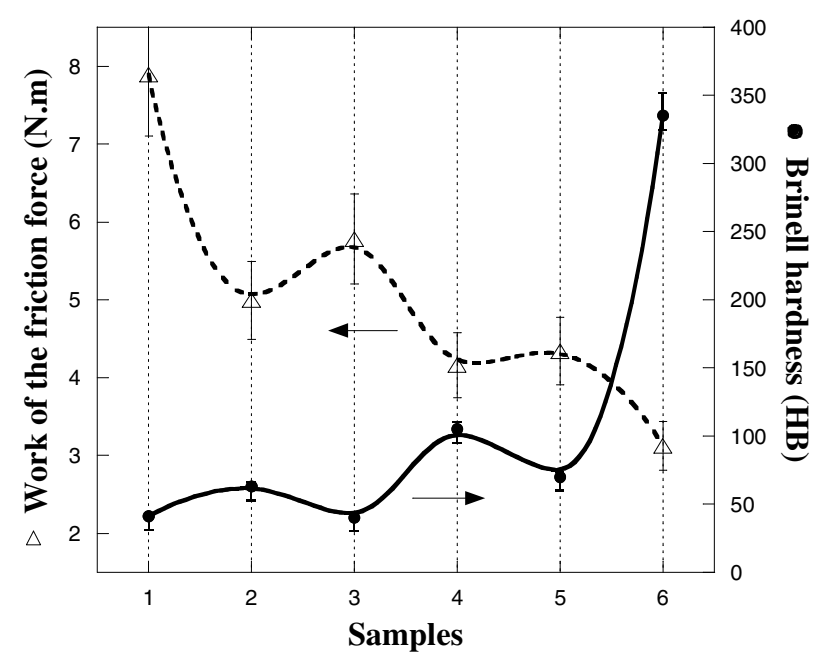

Figure 4. Brinell hardness and work of the friction force of the various samples listed in Table 3. Lines are only given to guide the eye. 


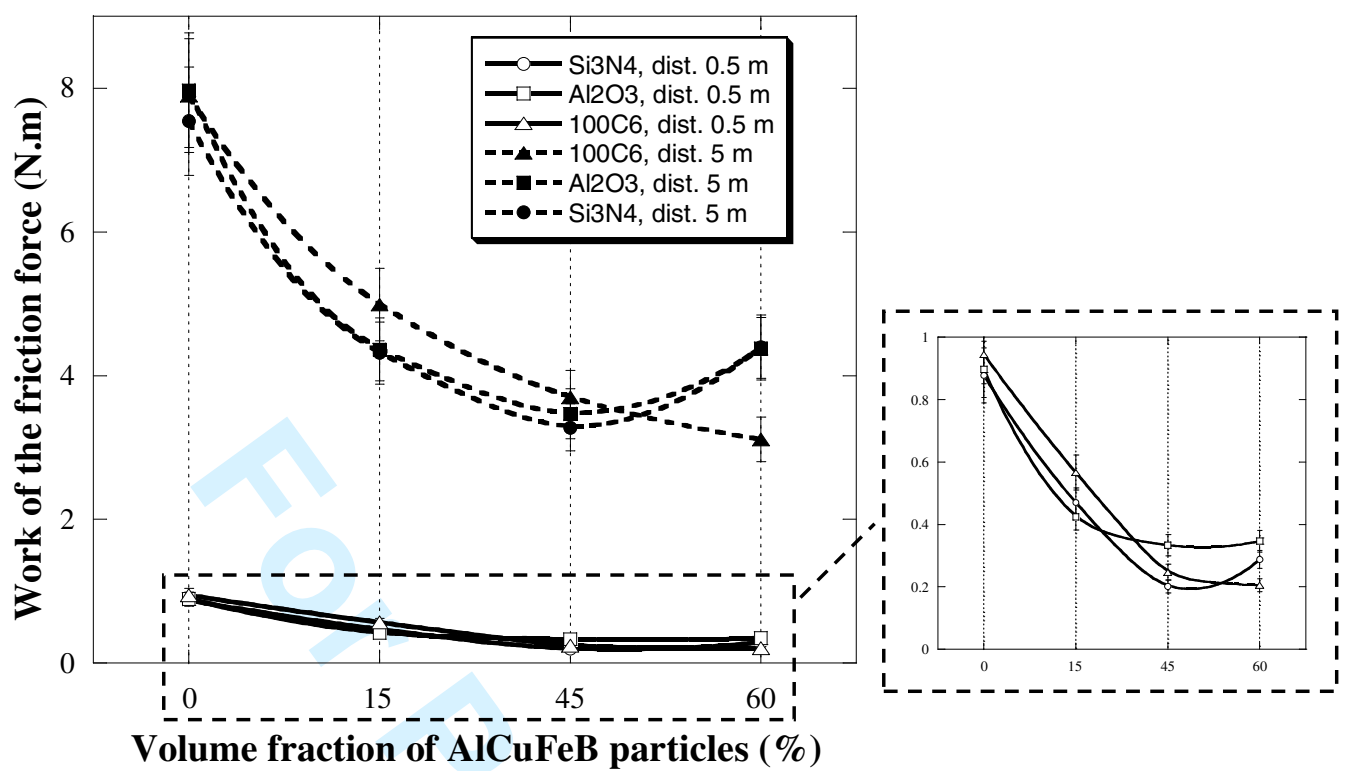

Figure 5. Dependencies of the work of the friction force with the volume fraction of AlCuFeB particles and the sliding distance for different indenters.

Table 4

Summary of the XRD analyses of samples.

\begin{tabular}{ccccc}
\hline Composite $^{\circ}$ & Vol.\% AlCuFeB & $\begin{array}{c}\text { Oxidation } \\
\text { Pre-treatments }\end{array}$ & $\begin{array}{c}\text { XRD } \\
\text { before sintering }\end{array}$ & $\begin{array}{c}\text { XRD } \\
\text { after sintering }\end{array}$ \\
\hline 0 & 0 & - & $\mathrm{Al}$ & $\mathrm{Al}$ \\
1 & 15 & - & $\mathrm{Al}+i+\beta$ & $\mathrm{Al}+\omega$ \\
2 & 15 & in air for $10 \mathrm{~h}$ & $\mathrm{Al}+i$ & $\mathrm{Al}+i+\omega$ \\
3 & 15 & in air for $100 \mathrm{~h}$ & $\mathrm{Al}+i$ & $\mathrm{Al}+i$ \\
4 & 30 & - & $\mathrm{Al}+i+\beta$ & $\mathrm{Al}+\omega$ \\
5 & 30 & $75 \mathrm{~h}$ & $\mathrm{Al}+i$ & $\mathrm{Al}+i+\omega$ \\
6 & 45 & - & $\mathrm{Al}+i+\beta$ & $\mathrm{Al}+\omega$ \\
\hline
\end{tabular}

Table 5

Mechanical properties of samples listed in Table 4.

\begin{tabular}{ccccc}
\hline Composite $\mathbf{N}^{\circ}$ & $\begin{array}{c}\boldsymbol{\sigma}_{\text {yield }}(\mathbf{M P a}) \\
\mathbf{\pm 1 0} \%\end{array}$ & $\begin{array}{c}\text { Hardness } \\
\mathbf{( H B})\end{array}$ & $\begin{array}{c}\text { Increase of } \\
\text { Hardness } \\
\text { compared to the Al matrix }\end{array}$ & $\begin{array}{c}\text { Increase of } \boldsymbol{\sigma}_{\text {yield }} \\
\left(\Delta \sigma_{0.2}\right)\end{array}$ \\
\hline 0 & 104 & $41 \pm 2$ & - & - \\
1 & 159 & $67 \pm 3$ & $26 \mathrm{MPa}, 63 \%$ & $55 \mathrm{MPa}, 53 \%$ \\
2 & 127 & $50 \pm 3$ & $9 \mathrm{MPa}, 21 \%$ & $23 \mathrm{MPa}, 22 \%$ \\
3 & 72 & $40 \pm 2$ & $-1 \mathrm{MPa},-3 \%$ & $-30 \mathrm{MPa},-31 \%$ \\
4 & 251 & $100 \pm 5$ & $59 \mathrm{MPa}, 143 \%$ & $147 \mathrm{MPa}, 141 \%$ \\
5 & 183 & $70 \pm 4$ & $29 \mathrm{MPa}, 70 \%$ & $79 \mathrm{MPa}, 76 \%$ \\
6 & 405 & $184 \pm 18$ & $143 \mathrm{MPa}, 348 \%$ & $301 \mathrm{MPa}, 289 \%$ \\
\hline
\end{tabular}

Note: All the indicated values correspond to an average value of at least 2 samples. 

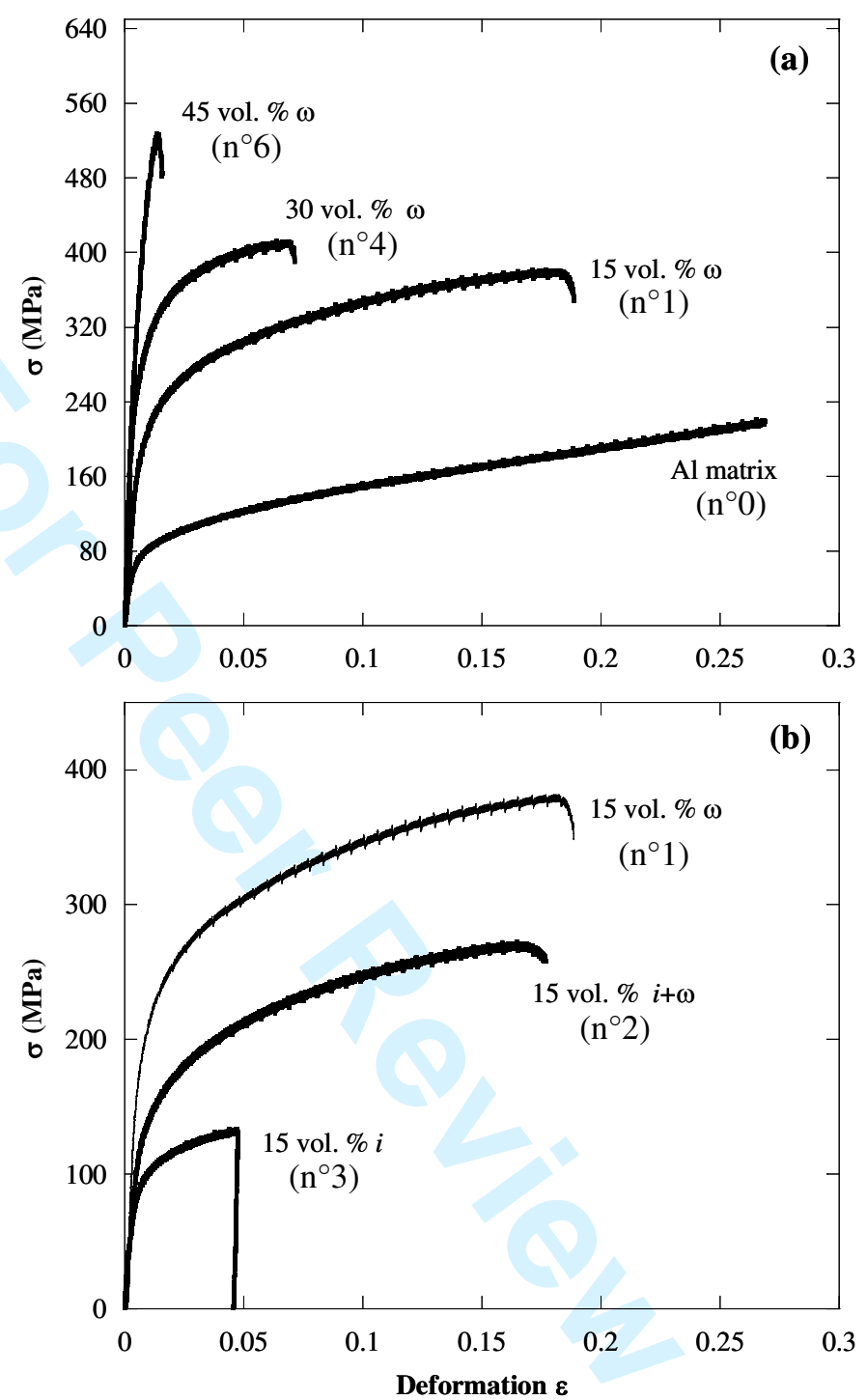

Figure 6. Comparison of the stress-strain curves of the $\mathrm{Al} /(\mathrm{AlCuFeB}) \mathrm{p}$ composites prepared with particles containing only the $\omega$-phase at different volume fractions (a) containing 15 vol. \% of pre-oxidized $\mathrm{AlCuFeB}$ particles (b). Composite numbers listed in Table 4 are given. 

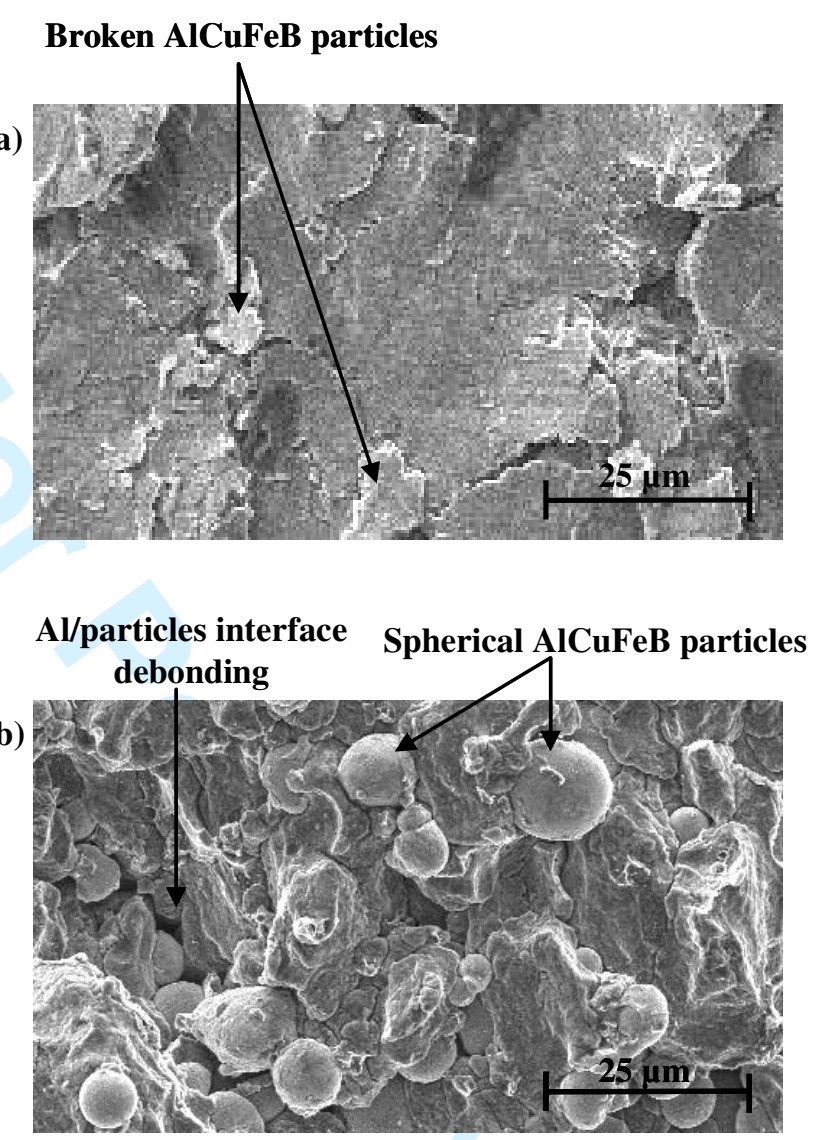

Figure 7. Representative fracture surfaces of (a) composite samples containing the $\omega$ phase and (b) the $i$ phase. 